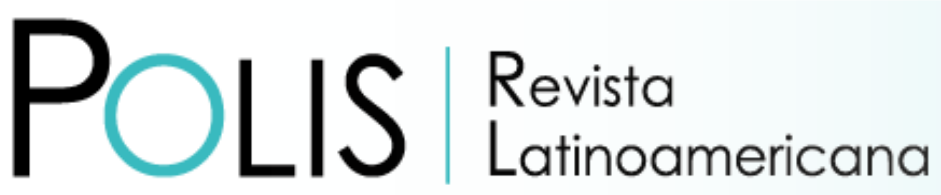

V20 | N59 | 2021

DOI: $10.32735 /$ S0718-6568/2021-N59-1474

\title{
Estudio de autopercepción de pequeños productores agrícolas. El caso de Huichapan Hidalgo, México
}

\author{
Sergio Gabriel Ceballos Pérez \\ Cátedras Conacyt - El Colegio del Estado de Hidalgo, Hidalgo, México \\ Email: sceballos@elcolegiodehidalgo.edu.mx \\ Griselda Nopal Tejamanil \\ Universidad Pedagógica Nacional, Campus Hidalgo, México \\ Email: griseldanopaltejamanil@upnhidalgo.edu.mx
}

Recibido: 05.03.2020 | Aceptado: 25.03.2021

\begin{abstract}
Resumen: En los últimos años los pequeños productores agrícolas (PPA) han experimentado fuertes cambios que les ha impedido realizar sus actividades agrícolas de forma adecuada; peor aún, las políticas públicas los han impulsado hacia el rezago y el abandono de sus tierras. La presente investigación se basa en un estudio de autopercepción, bajo la narrativa de cómo los campesinos se conciben así mismos frente a los cambios por el neoliberalismo y las razones de su persistencia para continuar trabajando el campo en defensa de su territorio. Como resultados se encuentran que el papel de los PPA es indispensable para el desarrollo local y regional, ya que existen más funciones sociales, culturales y ambientales que cumplen, más allá de las meramente económicas.
\end{abstract}

Palabras clave: Campesinos; espacio; cultura; conservación; pobreza.

\section{Study of Self-perception of Small-scale Farmers. The case of Huichapan Hidalgo, Mexico.}

\begin{abstract}
In recent years, small-scale agricultural producers have experienced strong changes that have prevented them from carrying out their agricultural activities adequately; worse still, public policies have driven them to lag behind and abandon their lands. This research is based on a study of self-perception, under the narrative of how peasants conceive themselves in the face of changes due to neoliberalism and the reasons for their persistence to continue working in the field in defense of their territory. As a result, it is found that the role of small-scale farmers is essential for local and regional development since there are more social, cultural, and environmental functions that they fulfill, beyond the merely economic ones.
\end{abstract}

Keywords: Peasants; Space; Culture; Conservation; Poverty. 


\section{Estudo da autopercepção de pequenos produtores agrícolas. O caso de Huichapan Hidalgo, México.}

Resumo: Nos últimos anos, os pequenos produtores agrícolas (APP) passaram por fortes mudanças que os impediram de desenvolver suas atividades agrícolas de maneira adequada; pior ainda, as políticas públicas os levaram a ficar para trás e a abandonar suas terras. Esta pesquisa fundamenta-se em um estudo de autopercepção, a partir da narrativa de como os camponeses se concebem diante das mudanças decorrentes do neoliberalismo e os motivos de sua persistência em continuar trabalhando no campo em defesa de seu território. Como resultado, verifica-se que o papel dos APPs é fundamental para o desenvolvimento local e regional, uma vez que são mais funções sociais, culturais e ambientais que cumprem, além das meramente econômicas.

Palavras-chave: Camponeses; espaço; cultura; conservação; pobreza.

Como citar este artículo:

Ceballos Pérez, S y Nopal Tejamanil, G. (2021). "Estudio de autopercepción de pequeños productores agrícolas. El caso de Huichapan Hidalgo, México. Polis Revista Latinoamericana, 20 (59), 165-184. doi: http://dx.doi.org/10.32735/S0718-6568/2021-N59-1474

\section{Introducción}

La agricultura y la situación económica y social de los pequeños productores agrícolas (PPA) representa para muchos gobiernos un problema pendiente resolver. La Organización de la Naciones Unidas para la Alimentación y la Agricultura (FAO, 2014) reconoce que existen más de 570 millones de explotaciones agrícolas en el mundo identificadas como familiares. En este sentido, los PPA juegan un papel social relevante, siendo importantes desde el abastecimiento de los alimentos (FAO, 2014), hasta ámbitos como la conservación de la cultura, la biodiversidad y su contribución ambiental y ecológica. Por ende, la FAO considera al pequeño agricultor como un actor clave para la erradicación de la pobreza, el fortalecimiento de la seguridad alimenticia, la polarización de desigualdades, la emigración, entre otros, fomentando así el desarrollo regional sustentable.

Los PPA tienen presencia en todo México, siendo particularmente importantes en el estado de Hidalgo, dónde la población rural representa el 47.8 por ciento del total (Instituto Nacional de Estadística y Geografía [INEGI], 2018). El resto de la población se concentra en las tres ciudades más grandes del estado, donde muchas personas viven debido a las oportunidades de empleo, educación y servicios. Los municipios de Hidalgo que se dedican a la agricultura (como Huichapan) tienen características similares, especialmente los que producen maíz, son comunidades con escasos servicios, alejados de los mercados, poca infraestructura y menor densidad poblacional (Soto, González y Carrillo, 2020; Fitting, 2007). Los campesinos en Hidalgo son en mayoría PPA, ya que dependen de las condiciones climatológicas, poseen escasa tecnología y comparten situaciones económicas similares entre sí (Quintero y Ceballos, 2007). 
Dicho sea de paso, estas estas comunidades son un reflejo claro de lo que sucede a nivel nacional. De acuerdo con Gómez y Tacuba (2017) la población total en México que se dedica al campo es de 5.5 millones de personas. Por su parte, Jarquín, Castellanos y Sangerman (2017) mencionan que un promedio del $41.5 \%$ no recibe algún tipo de pago por su trabajo al formar parte de un núcleo familiar agrícola.

Aunado a lo anterior, los PPA se han visto envueltos en una ola de políticas agresivas en contra de su territorio, su forma de producción y su forma de vivir (Robles, 2013).

El presente artículo deriva de una investigación de autopercepción que tuvo como objetivo principal conocer el motivo por el cual los pequeños productores agrícolas continúan haciendo su labor a pesar de las políticas neoliberales implementadas desde principios de los ochentas. Como objetivos particulares se buscaron identificar la importancia del pequeño agricultor a nivel regional y local; y describir la forma de reproducción social y expectativas desde la perspectiva misma del agricultor. El diseño de investigación se basa en observaciones de campo y entrevistas dirigidas a pequeños agricultores pertenecientes al municipio de Huichapan, con el fin de plasmar de manera más clara su persistencia al campo (Rizzo, 2012). En ese sentido, nuestra pregunta de investigación fue la siguiente: ¿̇Por qué los pequeños productores agrícolas continúan trabajando en el campo ante las enormes dificultades que representa?

\section{Exclusión de los pequeños productores agrícolas}

Diversos estudios indican que la agricultura a pequeña escala o familiar es una manera efectiva de erradicar la pobreza, alcanzar la seguridad alimentaria y contribuir a una forma de producción amigable con el medio ambiente como camino para el desarrollo regional sustentable (Terrazas, Garza y Cruz, 2019). A pesar de esto, no se le ha dado la importancia necesaria. Para lograr el desarrollo de la mayoría de estos grupos sociales, se requiere identificar su valor por medio de la justicia social y el respeto de los derechos humanos y de diversidad cultural (Coraggio, 2010).

Es por ello que los PPA representan un verdadero desafío ante la corriente de pensamiento económico dominante que ciegamente defiende la agricultura empresarial o agroindustrial, al considerarla como la única capaz de responder a las exigencias de la competitividad y calidad propias del mundo globalizado (Esteve, 2009). Lo anterior afecta seriamente a la mayor parte de los pequeños productores, quienes trabajan bajo condiciones de precariedad y riesgos de toda índole (cambios de clima, fluctuaciones del mercado, el escaso impacto de las políticas agrícolas, la poca remuneración, entre otros) y utilizan la mano de obra familiar y formas de cultivo tradicional (Bartra, 2009).

El modelo económico actual ha traído a los PPA un desarrollo desigual e inequitativo, debido a que el funcionamiento del sistema capitalista se basada en reglas de maximización de 
resultados, reducción de costos y acumulación de capital (Tortosa, 201 1). No obstante, esta lógica de progreso no aplica para la agricultura a pequeña escala, por el contrario, afecta su seguridad, libertad e identidad. Las cuales son trastocadas a través de las políticas agrícolas neoliberales propuestas por los gobernantes, empresas transnacionales y élites del mismo sistema capitalista. El cual considera que el mercado el único fin en todo momento (Guinjoan, Badia y Tulla, 2016). Se trata de un contexto de la globalización de los mercados, donde la competencia es la ley universal y el capitalismo es un proceso de innovación que destruye las fuerzas culturales tradicionales productivas, así como el desarrollo humano y ecológico (Navia-Antezana, 2008).

En ese sentido, el concepto de desarrollo ha sido ampliamente cuestionado, ya que excluye a poblaciones vulnerables poniendo como excusa la contribución del crecimiento económico de ciertas áreas geográficas (Bennett y Satterfield, 2018). El desarrollo debe retomarse desde una perspectiva diferente basada en la inclusión, tal como han expresado autores como Max-Neef (2010), Elizalde H. (2003), entre otros, quienes están a favor de implementar y fomentar las capacidades individuales y colectivas, dónde el rol del estado es proporcionar un piso parejo de oportunidades para el desarrollo de las personas (Acosta, 2010).

\section{Definición de los Pequeños Productores Agrícolas}

De acuerdo con (Chayanov, 1974) el sistema de producción campesino (que es el más cercano al sistema de los PPA actuales), constituye un sistema económico propio con un funcionamiento y racionalidad diferente al del sistema capitalista, donde los trabajadores laboran bajo factores de producción propios de la empresa clásica. Además, su lógica es diferente de la ganancia capitalista, ya que buscan el equilibrio entre producción y medioambiente, mantenimiento de los factores de producción y satisfacción de las necesidades de la unidad familiar (Feito, 2013). En ese sentido, la FAO, define a los PPA cuando tienen:

"acceso limitado a recursos de tierra y capital; hacen uso preponderante de fuerza de trabajo familiar, siendo el(la) jefe(a) de familia quien participa de manera directa del proceso productivo (...) dando pie a que exista una división de trabajo, el(la) je$\mathrm{fe}(\mathrm{a})$ de familia no asume funciones exclusivas de gerente, sino que es un trabajador más del núcleo" (FAO, 2012: p.6).

Haciendo referencia a un sistema de división de trabajo familiar y de producción agrícola con diversas limitantes y destino para el autoconsumo (Bruno, 2016).

Por su parte, la Secretaría de Agricultura en México, define a los PPA como "personas físicas o morales con actividad agropecuaria, pesquera y demás actividades económicas vinculadas al medio rural, que pertenezcan a los estratos E1, E2 y E3" (Diario Oficial de la Federación [DOF], 2016). La FAO (2012) señala que existe un total de seis estratos que se han identificados en México y de los cuales tres hacen referencia a los PPA: 
- El. Familiar de subsistencia sin vinculación al mercado;

- E2. Familiar de subsistencia con vinculación al mercado;

- E3. Estrato en transición.

\section{Los estudios de autopercepción de los Pequeños Productores Agrícolas}

Los estudios de autopercepción son una forma de acercarse al conocimiento desde una perspectiva privilegiada en donde los protagonistas son, a su vez, transmisores e intérpretes de su misma información, mediante el proceso de la narración de su realidad con el entorno en el que viven (Vences, Bolio y Bolio, 2017). "Los estudios de autopercepción en PPA son una necesidad para comprender la complejidad de la racionalidad de los agricultores frente a la resistencia del abandono del campo y para ser revalorados como actores clave para el desarrollo local y regional (Acosta y Cruz 2019).

De acuerdo con Loor, Alonso y Pérez (2019) estos estudios contribuyen al empoderamiento, y reconocimiento no sólo características negativas o limitativas como las señaladas anteriormente, sino también características positivas en los PPA, tales como:

- Uso de conocimientos tradicionales de domesticación de semillas regionales.

- Uso de métodos amigables con el medio ambiente.

- Uso de semillas criollas o semillas de cosechas anteriores.

- Venta de producción en mercados locales.

- Uso de producción que complementan otras actividades.

- Ejercen una forma de organización comunitaria.

- Apego a la tierra de forma cultural y social.

\section{Diseño de la investigación}

Derivado de lo anterior, el diseño de la presente investigación se basa en un estudio de autopercepción para conocer por qué los PPA continúan sembrando sus parcelas a pesar de las desventajas competitivas que enfrentan en el campo. Para ello, se utilizaron métodos cualitativos aplicados al estudio de caso, los cuales consistieron en observaciones realizadas en campo; de forma paralela se realizó un estudio exploratorio de autopercepción de los PPA, por medio de entrevistas estructuradas y a conveniencia, donde los participantes narran su estilo de vida, su percepción del futuro y las dificultades para la producción.

Los PPA que fueron entrevistados eran en su mayoría personas del sexo masculino (19 hombres y una mujer) poseedores de las tierras que trabajan. El rango de edad de los participantes oscila entre los 41 a los 81 años, teniendo un promedio de 59.7 años (siete adultos mayores y 13 adultos). 
Para las entrevistas se utilizó una muestra por conveniencia, esto significa que las entrevistas se realizaron a las personas que cumplieron con las siguientes características:

- Que estuvieran disponibles para ser entrevistados.

Ser considerados a sí mismos como un pequeño productor agrícola: contar con pocas hectáreas de producción y que el trabajo realizado sea familiar.

- Las personas que sean consideradas como parte de la muestra deben de aceptar y estar de acuerdo en proporcionar información real.

- Pertenecer a la zona geográfica donde se limita la investigación.

- Que el cultivo sea preferentemente maíz o haya sembrado maíz anteriormente (esto debido a que es un producto de autoconsumo)

- Preferentemente que sea un productor agrícola que se haya dedicado durante varios años a dicha actividad.

Los entrevistados seleccionados trabajan sus tierras y radican principalmente en las comunidades de Tlaxcalilla, Huichapan, San José, Jonacapa y Yonthé, todas ubicadas dentro del municipio de Huichapan, Hidalgo, México.

\section{Área de estudio}

El trabajo de investigación en campo se realizó en el municipio de Huichapan, en el estado de Hidalgo, debido a la considerable presencia de pequeños agricultores que se dedican a la siembra de maíz en comparación con el resto de los 83 municipios del estado.

El municipio de Huichapan está localizado en las coordenadas latitud norte 20,08,45 y longitud oeste 98,26,18. Ubicado hacia el oeste de la región del Valle del Mezquital, colinda con cuatro municipios hidalguenses (Alfajayucan, Chapantongo, Nopala y Tecozautla) y con el estado de Querétaro. Se caracteriza por estar localizado en una extensión de planicie, además de tener una región montañosa en la zona colindante con Nopala y poseer la Barranca del Gallo, por donde fluye bastante agua en temporadas de lluvia. En este sentido, las principales fuentes naturales de agua en Huichapan son: Arroyo Hondo, que cruza el municipio de norte a sur y la Presa Francisco I. Madero, que da origen a una unidad de riego. Esta después se une con el arroyo Nimacu, dando origen al río Tecozautla (Instituto Nacional para el Federalismo y el Desarrollo [INAFED], 2010).

El municipio se conforma por 87 localidades, tres son calificadas como urbanas y el resto como rurales. Huichapan tiene un índice de desarrollo humano (IDH) de 0.732/1, que es considerado como alto (PNUD, 2019) y se clasifica con un grado de marginación municipal medio (Consejo Nacional de Población [CONAPO], 2015). Tiene una población total de 45,959 habitantes, de los cuales el 12.29 por ciento de la población ocupada se dedica al sector primario (INEGI, 2015). Los habitantes están distribuidos en una extensión de 65,538 hectáreas (INAFED, 2010) y cada año se siembran aproximadamente el 25.2 por ciento de esta extensión (Sistema de Información Agroalimentaria y Pesquera [SIAP], 2016). 
Huichapan, es uno de los municipios con mayor concentración de superficie de siembra de maíz (60.2 por ciento) y con mayor superficie sembrada por pequeños y medianos productores (99.55 por ciento). Aquí se siembran 16 productos agrícolas anualmente, siendo el grano de maíz (60 por ciento) y el frijol (25 por ciento) los principales productos agrícolas (SIAP, 2016). Cuenta con 4,774.5 hectáreas de cultivo que cuentan con sistemas de riego, además de 11,741.1 hectáreas de temporal, que tienen una mayor dependencia del comportamiento climático.

\section{Resultados}

Los resultados del estudio se presentan de acuerdo con categorías analíticas basadas en preguntas reflexivas que se aplicaron en temáticas progresivas para guiar a los entrevistados, identificando primeramente las dificultades que enfrentan los PPA; la percepción de los programas de apoyo gubernamentales; las expectativas y preferencias de desarrollo y bienestar; $y$, por último, la importancia de los PPA para el desarrollo regional. Con estas cuatro categorías se identificaron los argumentos de la persistencia de los PPA y la importancia de su labor desde la perspectiva misma de los agricultores.

\section{Las dificultades que enfrentan los PPA para sembrar}

Las dificultades en el campo que los campesinos enfrentan para obtener su producción anual son muchas. No obstante, los problemas pueden ser menores dependiendo del contexto del campesino, de cómo trabaja cada uno y de cuánto tiempo le dediquen al mismo.

El principal reto dentro del ciclo de siembra es el cambio del clima, ya que los campesinos dependen de su comportamiento para iniciar el ciclo de siembra. El clima determina el tiempo de siembra. Entre más se atrasa el cultivo, la producción se hace más vulnerable, esto debido a que la siembra no crece lo suficiente para resistir la temporada de frio, el granizo y la escasa lluvia de los meses posteriores. En palabras de Eufrosina, agricultora originaria de Huichapan:

“... Sí, el cambio del clima, por ejemplo, este año no nos deja sembrar la lluvia, ha estado lloviendo bastante, todo eso verde no es maíz, es maleza que ha salido porque no se ha podido trabajar, es muy poco lo que se han sembrado y así está todo el ejido." (fragmento de entrevista, 12 de julio de 2018)

Las lluvias son un factor importante para los animales de granja, su otra fuente de ingresos. Cuando llueve, el pastizal crece en los cerros y los campesinos sacan a sus animales para que puedan alimentarse. En contraste, cuando no llueve, los animales son mantenidos en los corrales, implicando un gasto adicional. La falta de lluvia no es el único factor climático a considerar, también el exceso de esta, las temporadas de frio, sequía, granizo o nieve son importantes. Otra de las complicaciones es la hierba o maleza que crece en las tierras de 
cultivo, esta aparece durante todo el ciclo y es de crecimiento rápido y abundante. Si la maleza crece grande terminará acaparando espacio y evitando que el maíz se desarrolle adecuadamente.

Sin duda el cambio climático ha mostrado ser uno de los principales retos, así lo explica Jorge, agricultor de 50 años:

"...últimamente el calor se ha puesto muy fuerte o luego cuando llueve mucho se pasa de agua y se echa a perder el maíz, cuando llueve mucho, mucho, pues ahorita se me descompuso el maíz, se pone rojo, rojo y ya no. Ya nada más está como esta estatura y está roja la hoja y ya no produce porque se aguachina." (fragmento de entrevista, 12 de julio de 2018)

El clima en general determina qué tan productivo y próspero puede ser el año, considerando también que los apoyos gubernamentales puedan contrarrestar los impactos negativos del clima $u$ otras dificultades que afecten la producción y la economía de las familias campesinas. Además del clima, también existen otros factores importantes a tomar en cuenta como la falta de tiempo y las enfermedades, así el trabajo de campo se hace más complicado.

Aquí se hace énfasis en la importancia que tiene la tecnología en el trabajo de campo. El sistema de riego es de los más anhelados, ya que existe una mayor probabilidad de garantizar la producción sin necesidad de esperar las lluvias. Con maquinaria se realiza el trabajo de siembra con mucha mayor facilidad, más aún cuando se siembran muchas hectáreas. Por su parte, las semillas mejoradas tienen una mayor resistencia a las heladas y plagas, poniendo de lado sus efectos negativos. Considerando que la situación propia de los campesinos (enfermedad, economía, capacitación, etc.) y de su entorno (climatológico, inflación, plagas, etc.) afecta significativamente la producción y la estabilidad económica, Edilberto, agricultor de 77 años originario de Huichapan nos comenta:

"... Pues si no cuida uno el trabajo, sí. Por ejemplo, cuando se enyerba la milpa', si no se cuida se echa a perder, ese es el problema cuando se descuida uno... Por qué otros veo que va quitando la hierba con pala con azadón y tardan y les gana la hierba, cuando no es mucha si se puede, pero si tiene una, dos o tres hectáreas necesita trabajo rápido." (fragmento de entrevista, 11 de julio de 2018)

El agricultor que cuenta con un sistema de riego adquiere y paga el permiso del uso de agua y normalmente siembra a inicios de marzo. No obstante, la producción de temporal depende de las lluvias, sin estas, el agricultor no puede comenzar el ciclo de siembra. Su inicio puede variar desde marzo y hasta julio; entre más tarda, más probabilidades existen en perder la cosecha (véase Cuadro 1).

1 La milpa se refiere a un sistema prehispánico de cultivos sembrados estratégicamente para el autoconsumo y la conservación de los suelos, incluye principalmente maíz, y otros cultivos como chile, frijol, calabaza, o incluso algunas plantas como el quelite que son de gran aporte nutritivo o hierbas medicinales véase Bartra (2009). 


\section{Cuadro 1. Posible ciclo agrícola de temporal dependiendo de las lluvias}

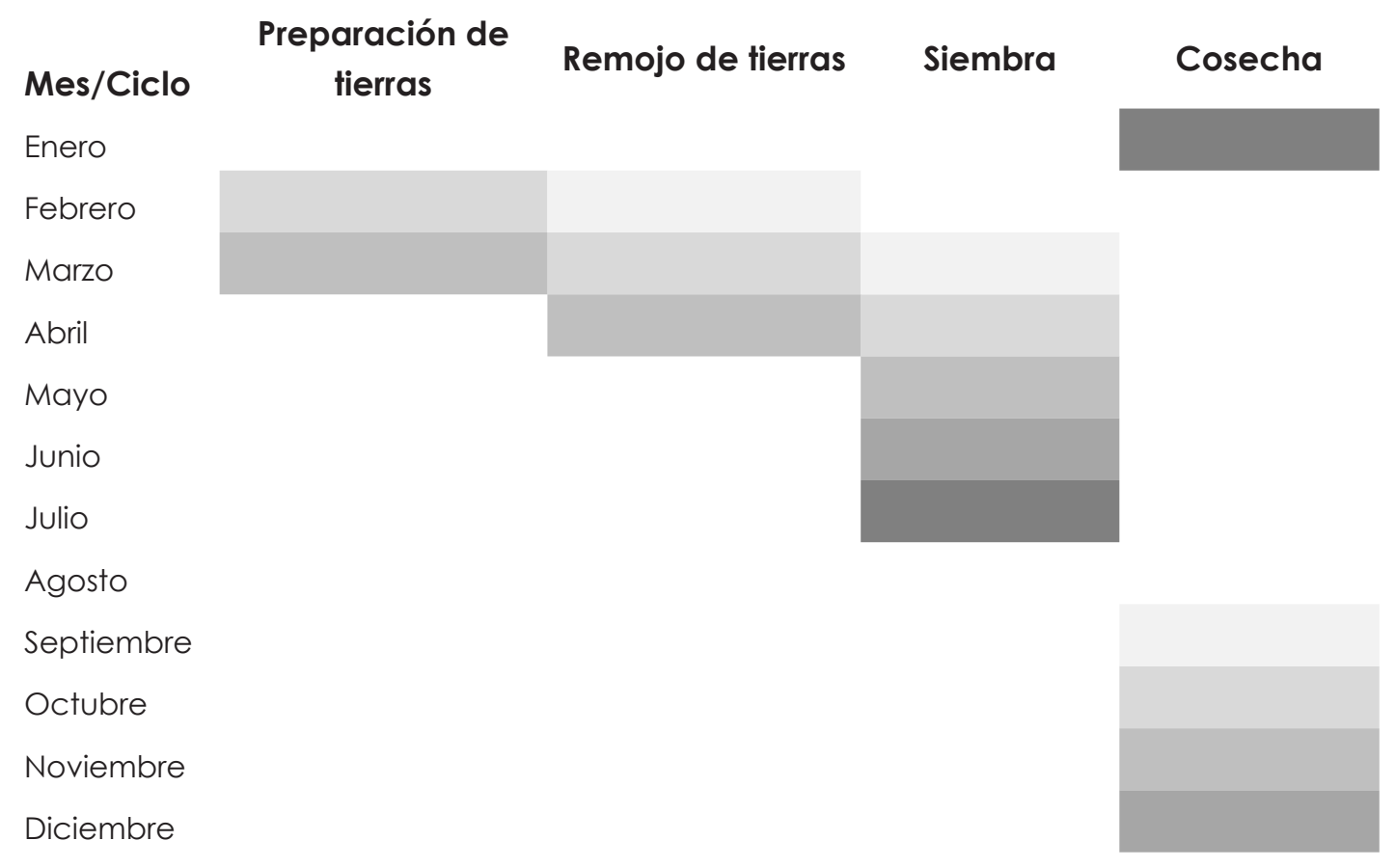

Fuente: Elaboración propia con información extraída de entrevistas realizadas en julio del 2018.

También, se depende del tipo de semilla, ya que el crecimiento del maíz puede variar desde cuatro hasta siete meses, tal como lo comenta Roberto, agricultor de Tlaxcalilla de 62 años:

"Cuando viene algo de lluvia pues sembramos en mayo-junio y ya ahorita estamos en julio, yo apenas fui a sembrar hoy y ni sembré todo, me faltaron dos hectáreas porque esta mojado. Y la mayoría nadie siembra por agua y ahora que llovió ya se cargó el agua y no podemos sembrar y ahorita la gente apenas anda queriendo sembrar." (fragmento entrevista, 10 de julio de 2018)

Una de las características de la unidad económica campesina es el apoyo familiar que tiene el jefe o la jefa de familia, que también es diferente dependiendo de cada situación y condición de trabajo en la que se encuentra el pequeño productor. Hay campesinos que reciben ayuda familiar durante todas las etapas del proceso de producción (sembrar, quitar la hierba, regar, cosechar, etc.). Sin embargo, también hay campesinos que tienen menos ayuda familiar, determinada por diferentes situaciones. Una de las razones que más se mencionó fue la cuestión del género, sobre todo hablando de las mujeres que son jefas de familia y tienen niños pequeños menores de 10 años; aunque también se comentaron otras, como la enfermedad o la falta de disponibilidad de los familiares.

Durante las entrevistas, dos campesinos afirmaron no requerir la mano de obra de su familia porque hacen uso de maquinaria para realizar el trabajo. Aunque, existen momentos del ciclo agrícola donde los PPA requieren el apoyo de mano de obra para evitar retrasos, en algunos de estos casos, Ios PPA deciden contratar a vecinos, conocidos o familiares 
lejanos. Las personas necesarias para este tipo de trabajos pueden ser desde una hasta tres, dependiendo de la etapa. La temporada más solicitada es durante la siembra, la cosecha (de una a dos semanas de trabajo cada una) y para quitar hierba. Los campesinos trabajan a su ritmo el resto de las etapas. Por otro lado, aquellos campesinos que tienen el apoyo familiar no contratan trabajadores durante casi todo el ciclo agrícola.

El trabajo de campo requiere de fuerza física, los productores reconocen que son actividades agotadoras tanto para ellos como para la familia. Son actividades que comienzan a realizarse desde muy temprano (en la madrugada) para evitar el calor del día, haciendo más difícil el trabajo. La fuerza física se usa en todo momento, por ejemplo, cuando se fumiga, se carga una bomba con aproximadamente 20 litros de fertilizante; también cuando se arranca la hierba, esta actividad se realiza con un azadón. Los campesinos consideran que el trabajo pesado del campo es una de las razones por la que los jóvenes ya no se quieren dedicarse a las labores rurales.

El uso de la maquinaria resulta importante durante los procesos de producción; sin embargo, cuando el campesino no cuenta con dicho capital, no tiene otra opción más que continuar trabajándolo de manera rudimentaria. Es más complicado cuando el campesino siembra más de una hectárea sin disponibilidad de maquinaria, realizar las actividades manualmente resulta prácticamente imposible. Por otra parte, el tiempo que se dedica al trabajo de la tierra también resulta relevante. Para Mario, agricultor de San José:

"Depende cuantas horas quieran trabajar también. Es depende el trabajo que te toque porque hay diferencia en cortar, cosechar, deshierbar, cortar el maíz todo eso. Hoy en día hay mucha tecnología también, como cosechar con maquinaria, pero nosotros no tenemos maquinaria para cosechar y tenemos que cosechar a mano". (fragmento de entrevista, 11 de julio de 2018)

De manera concreta, las tres cuestiones principales que influyen en la productividad son: el clima, el apoyo familiar y la disponibilidad de la tecnología y/o maquinaria. Esto puede variar de campesino a campesino, pero es un indicador de la eficacia de la producción final.

Algunas de las necesidades del campo pueden ser subsanadas con algunos de los programas gubernamentales o no gubernamentales. Sin embargo, el panorama es poco alentador para los campesinos que no son beneficiados, los cuales en ocasiones se ven obligados a abandonar las labores y optar por otras actividades, como los más jóvenes. En conjunto, todos son factores importantes que han influenciado el rumbo del trabajo en el campo.

La producción también se ve afectada por el surgimiento de plagas que se han convertido en un problema común entre los campesinos que merma la producción, como el chapulín que impide que las plantas crezcan o el gorgojo, que aparece posterior a la cosecha.

La situación económica desfavorable es un factor desalentador para los campesinos; sin embargo, se sienten agradecidos porque sus tierras les siguen dando alimento, haciendo 
del maíz más que un grano. Por tal motivo, sin importar el grado de estudios que obtengan sus hijos, consideran relevante que conozcan como cultivar y preservar los conocimientos de la tierra. En palabras de Fernando, agricultor de 68 años:

"...porque el campo es una ilusión del campesino, es una vida del campesino, el campesino vive del campo, el campesino es del campo, de ahí nos mantenemos cuando nos va bien, los campesinos que estamos en el pueblo de ahí es nuestra única esperanza, porque si nos va bien en la siembra, pues bien, y si no pues tenemos un animal, tenemos algo y si la vemos negras pues los vendemos, no queda de otra, para comer o para curarnos" (fragmento de entrevista, 12 de julio de 2018).

Así mismo, para la mayoría de los pequeños productores, es de suma importancia que sus descendientes (hijos o nietos) continúen trabajando sus tierras, aunque son conscientes de que no pueden obligarlos. Los campesinos buscan mínimo un heredero, teniendo preferencia por los hijos varones, probablemente por la fuerza de trabajo necesaria o por costumbre. La herencia es más que una parcela, es el trabajo de toda una vida, es ejercer los conocimientos adquiridos y se considera una tradición, es ejercer lo que los PPA son y lo que une a la familia.

Los campesinos también reconocen el desinterés que las nuevas generaciones tienen por el campo, incluso temen porque sus tierras sean vendidas o abandonadas cuando ellos ya no las trabajen. Por tal motivo, los hijos, que por lo general desean estudiar alguna profesión, los impulsan a ejercerla, pero sin dejar el campo. A pesar de la incertidumbre, el campesino continúa trabajando sus tierras mientras aún pueda hacerlo.

Aparte del valor tradicional y del esfuerzo que le imprimen cada día a su trabajo, para el pequeño agricultor de Huichapan es importante sembrar el maíz por su uso básico. Por el autoconsumo de elote, maíz y hoja que tiene una variedad de preparaciones. El grano se puede almacenar para abastecer durante todo un año.

Para un pequeño productor de maíz, trabajar el campo es más que sólo obtener el grano, es la base para la construcción de sus vidas. Es una herencia que adquirieron de generaciones anteriores y representa una inversión de tiempo y esfuerzo de muchos años. Para los agricultores resulta relevante sembrar maíz como parte de sus actividades, que en ocasiones es lo único que cubre sus necesidades. Ahora, con los cambios de clima, tecnología y métodos el campesino se ha estancado y lo ha relegado, al no estar a la par del cambio de las nuevas necesidades de la sociedad y el mercado. 


\section{Percepción de los programas de apoyo por parte de los PPA}

De acuerdo con estudios previos, en apariencia, en el país existen un gran número de programas agrícolas dedicados a pequeños productores. Sin embargo, la mayoría de los campesinos entrevistados dijeron desconocer sobre los programas gubernamentales, sólo algunos mencionaron conocer un par de programas, sin necesariamente ser beneficiados.

Los PPA en general mostraron disgusto ante los programas ofrecidos por el gobierno. Los consideran como un engaño y una pérdida de tiempo, ya que, para poder ser beneficiado, se les pide asistir a reuniones, proporcionar documentación, inscribirse y formar parte de una asociación política. Aseguraron también que realizaron varios intentos por seguir todos los requisitos, pero el apoyo se les negó. Mencionan que optaron por no desgastarse intentando obtener un apoyo que no se les va a brindar o va a tener un bajo impacto. En palabras de Adrián, agricultor de 52 años:

"...nunca nos han dado, nada más nos prometen... de SAGARPA no, no le pongo mucha atención y porque ya nos tienen artos, nos llaman y nos llaman y reuniones, para mi es pérdida de tiempo. No es porque a lo mejor voy a tener algo, pero ya cuando sé que es de gobierno, realmente todos estamos cansados de eso, nos quitan el tiempo, yo tengo mi trabajo, yo como les digo: oyes tú estás ganando, yo no, al contrario, estoy perdiendo. Ellos con que nos saquen fotos y todo ya muestran allá que ya trabajaron, pero realmente no nos apoyan. Entonces yo a mi gente les digo si hacemos cuentas de horas hombre perdidas en una reunión, pues mejor no nos ayuden." (fragmento de entrevista, 10 de julio de 2018)

Debido a los contratiempos que han experimentado los campesinos con los programas federales, algunos productores han optado por integrarse en asociaciones; por ejemplo, Antorcha Campesina, con el propósito de obtener apoyos para complementar los gastos que deben realizar cada año. Además, los campesinos se conocen entre ellos y conocen sus preferencias partidistas, lo cual también ha generado un problema ya que no comparten la misma ideología política. La mala distribución de la información y la obtención de los apoyos de forma no homogénea ha generado un problema dentro del mismo municipio, como lo comenta Fernando otro de los entrevistados que si cuenta con apoyo:

"...tengo Procampo, pero lo dan cuando quieren, nos dijeron que depende si ganaban o perdían. Aquí, sí es así [...] aparentemente el municipio es grande, pero nos conocemos casi todos los agricultores, así como nos conocemos como agricultores nos conocemos como partidistas, si tú eres priista te lo dan antes de tiempo, si yo soy panista no lo tengo todavía, si él es perredista tampoco se lo van a dar [...] pero eso no tendría que ver una cosa con la otra, y muchos están descontentos por eso, porque se supone que es para todos, pero así nos engañan..." (fragmento de entrevista, 10 de julio de 2018)

El desinterés de los campesinos hacia los programas gubernamentales los ha llevado a ignorar los objetivos de la política agrícola, sólo algunos tienen una noción de la importancia de los programas. Manifestaron que, años atrás, tenían completo interés por la información de los programas, cuando buscaban modernizarse: asistían a reuniones, buscaban representantes municipales y estatales, entre otras. La falta de respuestas y el incumplimiento provocó que 
los campesinos comenzaran a trabajar por su cuenta. Ellos desean modernizarse, mejorar la calidad de sus productos y competir en los mercados, pero los campesinos saben que no cuentan con el conocimiento ni con el capital necesarios. Dichos acontecimientos han alejado a los PPA de la información y los procesos necesarios para obtener los apoyos.

La producción de los campesinos les permite alimentarse durante el año y en ocasiones es suficiente para vender y poder cubrir otras necesidades. Sin embargo, aseguran que no es suficiente para solventar por completo a sus familias. Las personas que manifiestan que si pueden subsanar todos sus gastos familiares son, por lo general, parejas adultas que viven solas. Por otra parte, las personas que dicen no producir los suficiente, pertenecen a núcleos familiares grandes, donde los padres viven con hijos y nietos que son dependientes.

El precio de venta del maíz no ayuda a los campesinos a obtener suficientes ingresos. En temporadas de cosecha de maíz (de noviembre a enero), este se ofrece en $\$ 3.50 \mathrm{mxn}$ el cuartillo (un kilo y medio aproximadamente) y en el resto de los meses (de febrero a octubre), su precio puede variar de $\$ 3.50$ hasta $\$ 6.00$ el cuartillo. Debido a lo anterior, los campesinos buscan complementar sus ingresos realizando otras actividades como la cría de animales de ganado (borregos, conejos, gallinas, chivos, vacas y hasta caballos). Los campesinos que cuentan con un sistema de riego para siembra, tienen la posibilidad de producir forraje para sus animales (ya que este requiere de agua con frecuencia). Por tal motivo, se considera que contar con un sistema riego eficiente es una gran ventaja para la producción agrícola y por ende, para su economía.

A pesar de que el ganado complementa los gastos, algunos integrantes de la familia también optan por empleos de temporada (obrero, albañil, entre otros) para cubrir los gastos mientras esperan la temporada de cosecha.

En tiempos difíciles los campesinos deciden dejar sus tierras y a su familia para migrar a otros lugares en búsqueda de mejores oportunidades (por ejemplo, a Estados Unidos de América o a la Ciudad de México); una decisión difícil, cuando la cultura o el idioma son diferentes. En muchas ocasiones los campesinos sufren discriminación, por ejemplo, por su escaso nivel de estudios, su idioma, procedencia, apariencia, entre otros. Los campesinos mencionan que el trabajo, la experiencia y el conocimiento que adquirieron fuera del campo les fue de ayuda para poder invertir y continuar con sus actividades agrícolas en Huichapan de una mejor manera. En contraste, las personas que no migraron. siempre se han dedicado a ser campesinos, ganaderos y jornaleros. Así lo menciona Ricardo, agricultor originario de Yonthé:

“... Sí, Estado Unidos, el famoso sueño americano. Que muchos no estaríamos bien si no hubiéramos ido allá, yo fui por poquito tiempo. Especialmente si lo sabes aprovechar; haces cosas. Si vas a regresar en 10-20 años, regresas peor, eso lo tengo también presente y conozco gente que es así, entonces te acostumbras a la vida de allá y ya no quieres pisar el suelo. Para mí no era mi ilusión, yo regresé a mi pueblo, y nada más descansé dos-tres días y a seguirle con mi chamba del campo." (entrevista personal, 10 de julio de 2018) 
"... Cuando era joven, sí me iba a México, pero ahorita ya no, de que nos dedicamos al campo y ya tengo mi edad..." (entrevista personal, 10 de julio de 2018)

Los campesinos han tenido dificultades para producir en el campo como lo desearían. No han obtenido la respuesta que ellos buscan y que les ayude a fortalecer el desarrollo de las actividades del campo. A pesar de las dificultades, piensan que los apoyos pueden ser y son de gran ayuda para mejorar la producción, pero manifiestan que estos son concentrados en solo unos pocos.

\section{Expectativas y preferencias de bienestar de los PPA}

A pesar de las dificultades de producción, de pocos ingresos o perdidas, los campesinos comentan ser felices y disfrutar realizar las actividades del campo. Los campesinos se sienten satisfechos cuando ven sus esfuerzos traducidos en un paisaje verde de maíz.

Reconocen que dedicarse a la agricultura como negocio y como actividad para sustentar sus necesidades familiares resulta un enorme reto, no obstante, tratan de aprender de sus experiencias en el campo y de mejorar sus actividades agrícolas. Así lo confirma Rubén, agricultor de 62 años:

"...estoy acostumbrado a trabajar, trabajo en el campo y yo amo mi trabajo, cuando uno trabaja en el campo y deberás sabe cuidar la siembra, se da." (fragmento de entrevista, 11 de julio de 2018).

Trabajar las tierras y obtener una buena cosecha es la mayor expectativa que tienen los productores, independientemente de su edad y la falta de recursos. Ellos mencionan que desearían trabajar una mayor cantidad de hectáreas para obtener una mayor producción; introducir nuevos productos sin dejar de sembrar maíz, por ejemplo frijol, legumbres, tomate, cebolla, alfalfa y garbanzo; acceder a un sistema de riego para no depender de las lluvias y no ser afectados por el cambio climático; tener acceso a las nueva tecnologías (por ejemplo, invernaderos) para mejorar su producción; así como poder conocer y aprender sobre nuevas prácticas y culturas de lugares diferentes a los de la región donde se encuentran. Algunos campesinos ya han intentado cultivar nuevos productos, sin embargo, les falta capacitación y orientación, esto pone en riesgo su inversión agrícola.

Las contemplaciones de nuevas metas se concentran en mejorar sus condiciones económicas, aquellas que les permita trabajar sus tierras, llevan a la concientización de innovar para mejorar sus formas de producción. Los campesinos que no cuentan con metas definidas son porque están desanimados, ya que no tienen quién continúe trabajando sus tierras cuando ellos ya no puedan hacerlo o porque consideran que su forma tradicional para trabajar en el campo es mejor y no consideran los cambios tecnológicos como necesarios, sino todo lo contrario. Por ejemplo, aplicar abono orgánico en lugar de fertilizantes, para evitar la descomposición de la tierra con salitre. 
Otro aspecto muy importante es que los campesinos consideran que su vida en el campo es mucho mejor a la que tendrían si vivieran en una ciudad. Muchos han viajado y experimentado la vida de la ciudad y al parecer, se ven en una mejor situación si continúan viviendo en el campo como agricultores. Trabajando el campo, experimentan la tranquilidad y la libertad, disponen de alimentos sanos, agua y aire limpio y se sienten con propósito al trabajar las tierras. Por el contrario, manifiestan que una vida en la ciudad es estresante, con el peligro de ser asaltado, hay violencia, contaminación en el aire y en los alimentos, con un estilo de vida donde existe un sistema de intercambio basado totalmente de forma monetaria: sin trabajo no hay dinero, sin dinero no hay comida. No hay donde vivir y ellos saben que sólo pueden aspirar a ser obreros, o bien, con su edad, a no tener empleo.

Algunos consideran que dependiendo de las circunstancias en las que se encuentren, podrían vivir bien en la ciudad si tuvieran estudios, pero para ellos el campo es mejor. En palabras de Rómulo, agricultor de 44 años:

"Yo mil veces en el campo, porque aquí ahora sí que hay, aunque sea nopalitos, quelites, todo eso, y en la ciudad imagínate todo a comprar. Aquí ahora sí que respira uno el aire fresco, no contaminado, porque en la ciudad hay mucha contaminación" (fragmento de entrevista, 11 de julio de 2018)

Los campesinos consideran relevante la siembra de maíz, tanto para ellos como para los demás, ya que no producir maíz puede traer consecuencias graves. Algunos piensan que sería imposible que el campo se abandone junto con la siembra de maíz; sin embargo, una de las reacciones más comunes fue la tristeza. El abandono del campo provocaría que la migración hacia las ciudades aumente, también causaría una enorme pobreza, aumento de las importaciones de semillas extranjeras, escases de animales de granja y por supuesto, crisis económica. Los campesinos relatan el escenario de la derrota del pequeño productor, la perdida de las tradiciones y un desastre sin futuro. Muestran preocupación por los jóvenes que no les gusta el campo y no quieren trabajar. En este sentido, sienten preocupación por sus hijos y les tratan de enseñar a sembrar y tener animales, de invertir en el campo, si algún día ya no tienen trabajo o enferman. Gerardo, agricultor de 52 años de Yonthé nos comenta:

"...si dejáramos de cultivar el campo, me muero yo y se muere usted. Porque ¿̇quién va a cultivar para que los demás coman? por decir, los licenciados que jamás se van a meter al campo, pero ¿̇ellos compran tortillas?, y żquién lo cultiva? El agricultor. Como quiera que sean dependen de un agricultor. El día que dejemos de cultivar el campo sería un desastre dejar el campo. Se imagina al no cultivar las tierras se nos viene para abajo, todo, animales, no habría consumo de animales..." (fragmento de entrevista, 12 de julio de 2018)

Los campesinos consideran que el abandono del campo resultaría en una situación negativa generalizada que afectaría a los agricultores y al resto de la población. Los pequeños productores no están negativos ante las nuevas formas de producción, ni de la introducción de productos diferentes al maíz; por el contrario, están dispuestos a aprenden e introducir 
otras tecnologías para mejorar su producción. La relación entre las nuevas tecnologías y el nuevo conocimiento deben integrarse con respeto y con la intención de apoyar las formas tradicionales de trabajar el campo que han adquirido de generaciones anteriores.

\section{Los PPA como elemento clave para el desarrollo regional}

De acuerdo con estudios realizados sobre la importancia de la participación del pequeño productor agrícola como clave para el desarrollo regional, la agricultura, debe ser impulsada y considerada de gran importancia dentro de las actividades económicas, sociales, culturales y ambientales (Coraggio, 2010). Esto se debe a la relación territorial que tienen las comunidades entre sí, su tradición y a la composición comunitaria de los pequeños productores integrada por un sistema de producción agrícola de tipo familiar que tiene un bajo impacto negativo en el medio ambiente que fortalece las actividades económicas locales.

Los pequeños productores agrícolas están constituidos por un sistema económico propio basado en un funcionamiento y racionalidad diferente a la racionalidad capitalista. Esto significa que su objetivo principal no es la acumulación de bienes materiales, sino la distribución y fortalecimiento de su cultura que es transmitida de forma familiar, buscando mantener el equilibrio entre su producción, el consumo para la unidad familiar y la conservación de sus tierras.

La información arrojada en campo hace hincapié en el hecho de que los pequeños productores de maíz tienen un concepto de desarrollo diferente al que se conoce en las ciudades. Lo que se debe de buscar entonces es que, los productores puedan seguir sembrando sus cultivos, pero con el uso de mejores herramientas tecnológicas, siempre mediante el respeto y la permanencia de los procesos de cultivo tradicionales. Se debe de buscar el uso de las nuevas tecnologías sin desplazar las anteriores con la intención de fortalecerlas mutuamente.

Lo anterior ayudará a que la población continúe con sus actividades de siembra de la forma que ellos consideran es la más apta y que contribuye a formar su propio patrimonio sin la necesidad de acumulación de bienes. A largo plazo esto se traduce en una revalorización y repoblación de lo rural y no en un rechazo de lo que hoy se concibe como subdesarrollo y pobreza. La forma sustentable de producción que tienen los pequeños productores de maíz puede contrarrestar algunos de los problemas sociales que hoy en día se experimentan tanto en ámbito rural como en el urbano.

El fortalecimiento del conocimiento tradicional es una forma amigable de cultivar las políticas agrícolas con la sociedad y con el medio ambiente. Aún se habla de millones de personas que pertenecen a este ámbito y que no han podido ser absorbidas por las "modernidad" y los cambios económicos. El apoyo a la conservación de la agricultura a pequeña escala les permitiría a los campesinos continuar con sus conocimientos y formas de producción sin ser afectados por los cambios que surgen por el neoliberalismo, permitiendo el apropiado desarrollo de la sociedad rural a un ritmo e ideología adecuados para los mismos. 


\section{Reflexiones finales}

Los pequeños productores agrícolas siembran el maíz bajo una forma de trabajo familiar, significa trabajar las tierras que se han adquirido mediante el esfuerzo de sus antecesores. Trabajarlas significa apropiarse del pensamiento familiar y hace que sea necesario imprimir el mismo empeño. Por tal motivo, como respuesta a la pregunta de investigación, basándose en la tradición que tienen los agricultores sobre la siembra de maíz y de otras semillas, se hace expreso su impulso para continuar trabajando el campo año tras año, pese a la imposibilidad de integrarse por completo al estilo de vida occidental.

Los agricultores visualizan el trabajo de campo como una ventaja ante su situación actual de educación, edad y trabajo. Es un aprecio hacia el poco capital con el que cuentan, estableciéndose como afortunados cuando lo comparan con vivir en una ciudad. Para el pequeño productor agrícola, tener desarrollo significa contar con todas las herramientas necesarias para explotar sus tierras, completar el ciclo de su trabajo de campo y permanecer en el ámbito rural con su familia. También son conscientes de que necesitan y están dispuestos a aprender y adoptar nuevas técnicas, pero sin perjudicar su persona y su entorno. Mejor aún, ellos podrían contribuir a mejorar su entorno debido a la preocupación que tienen ante el desinterés de jóvenes y la mercantilización que se le dado a la invaluable semilla, traduciéndolo únicamente en unidades monetarias y de competencia.

Los productores están conscientes de que el maíz y otras semillas (calabacita, frijol, chile, café, etc.) son transmisores de conocimiento tradicional y cultural, domesticación de semillas, conservación y uso amigable de la tierra ante el medio ambiente. Estas en conjunto, forman parte de sus actividades diarias, su alimentación, costumbres y trabajo de la tierra; por ende, defienden dichos ideales, como el mantenimiento del maíz criollo, y han considerado como una amenaza algunas de las implementaciones que el estado ha intentado proponer.

El valor intrínseco que tiene pequeño productor agrícola es la producción de alimentos, en este caso de maíz, que transmite y conserva el conocimiento tradicional de métodos de siembra y plantas de generación en generación, un aprecio al trabajo de la tierra, los animales y del ámbito rural. Simultáneamente, fomenta una forma de producción que forma parte de una distribución más equitativa de alimentos, riqueza y solidaridad; así como fomentar una forma de producción más ecológica y conservacionista. En otras palabras, es una identidad de memorias colectivas en una concepción campesina vinculada con el campo. Se contemplan ciertos mecanismos, como el lugar donde radican, su familia, el trabajo de campo y sus tradiciones. Es una visualización de formar parte de la naturaleza y no de dominio de esta, basada en un conjunto de conocimientos ancestrales y conocimientos actuales.

Esto requiere de esfuerzos y de cambios dentro de la políitica agrícola y de los representantes, donde pongan por delante los objetivos de contribución al desarrollo antes que los intereses personales. De tal forma que los PPA y la ciudadanía en general vuelvan a confiar en 
los planes que establecen los programas de apoyo gubernamentales. Tales esfuerzos también contribuirán a contrarrestar el continuo abandono del campo por parte de la mayoría de los jóvenes que actualmente no contemplan la agricultura como parte de sus vidas.

Cada territorio regional de pequeños productores agrícolas difiere de otros, por tal motivo cada uno tiene condiciones diferentes de tierra, de clima y de semillas. Dichas condiciones ayudan a la identificación de necesidades regionales que les permiten contribuir al desarrollo del sector agrícola y del bienestar de la población rural. Reiterando que el estado debe de construir con su labor y con objetivos un estado de derecho para los pequeños productores agrícolas, que al mismo tiempo se traduzca en un derecho al desarrollo para este actor clave.

Trabajar en el campo es complicado, no obstante, tiene un significado relevante y profundo para los pequeños agricultores. Trabajar el campo se trata de algo más que solo producir, para ellos se trata de conservar las tradiciones del campo a través de la práctica y la aplicación de los conocimientos adquiridos; es la ilusión del campesino, es una vida, es la esperanza de cada año, es tener principios y cultura, es alimento y es salud. Para el campesino es importante conservar y transmitir el conocimiento de generación en generación. Este conocimiento diverso y único varía de acuerdo con la zona, las circunstancias de la tierra, el clima y la gente. En otras palabras, se sigue trabajando el campo como parte de su tradición como sinónimo de bienestar.

\section{Bibliografía}

Acosta, A. (2010). El Buen Vivir una utopía por reconstruir. En J. Sempere, A. Acosta, S. Abdallah, y M. Ortí, (Coord.). Enfoques sobre bienestar y buen vivir. (pp. 11-29) Madrid, España. Centro de Investigación de la Paz.

Acosta D. y Cruz J. (2019). Presencia y lugar del pequeño productor campesino en el Ecuador actual. Economía y Desarrollo, 162(2). 1-16. Recuperado de: https://www.redalyc.org/jatsRepo/4255/425560735004/html/index.html

Bartra, A. (2009). Hacer milpa. Ciencias, 92(1), pp. 42-45. Recuperado de: https:// www.revistacienciasunam.com/images/stories/Articles/92\%2093/Breve03/ Hacer\%20milpa.pdf

Bennett, N. J., y Satterfield, T. (2018). Environmental governance: A practical framework to guide design, evaluation, and analysis. Conservation Letters, 11 (6), 1-13. Recuperado de: https://doi.org/10.1111/conl.12600

Bruno, R. (2016). Desigualdade, agronegócio, agricultura familiar no Brasil. Estudos Sociedade e Agricultura, 24(1),142-160. Recuperado de: https://revistaesa. com/ojs/index.php/esa/article/download/712/452/2106

Chayanov, A. (1974). La organización de la unidad económica campesina. Buenos Aires, Argentina. Ediciones Nueva Visión SAIC.

CONAPO. (2015). Datos abiertos del índice de marginación. México. Secretaría de Gobernación. Recuperado de: http://www.conapo.gob.mx/es/CONAPO/Datos_Abiertos_del_Indice_de_Marginacion

Coraggio, J. L. (2010). Desarrollo regional, espacio local y economía social. Versión revisada de la ponencia presentada en el Seminario Internacional Las regiones del Siglo XXI. Entre la globalización y la democracia local, organizado por el Instituto Mora. Ciudad de México, México. Recuperado de: https:// www.econo.unlp.edu.ar/frontend/media/92/10992/0ecebc231 fb21351 ebdf981c2alfba95.pdf 
DOF. (31 de diciembre de 2016). Reglas de Operación del Programa de Apoyos a Pequeños Productores. Diario Oficial de la Federación. Secretaría de Gobernación. http://www.dof.gob.mx/nota_detalle.php?codigo=5468361\&fecha $=31 / 12 / 2016$

Elizalde H., A. (2003). Desde el desarrollo sustentable hacia sociedades sustentables. Polis, Revista de la Universidad Bolivariana, 0. Recuperado de: https:// wWw.redalyc.org/pdf/305/30500411.pdf

Esteve, M. (2009). Tierra y agua para poder producir y vivir: El Movimiento Campesino Cordobés. THEOMAI. Estudios sobre sociedad y desarrollo. 1 (20), 186-200. Recuperado de: http://revista-theomai.unq.edu.ar/NUMERO20/1 1 ArtEsteve. pdf

FAO. (2012). Marco estratégico de mediano plazo de cooperación de la FAO en Agricultura familiar en América Latina y el Caribe 2012-2015. Recuperado de: http://www.fao.org/3/as169s/as169s.pdf

FAO. (2014). Agricultura Familiar en América Latina y el Caribe: Recomendaciones de Política. Recuperado de http://www.fao.org/docrep/019/i3788s/ i3788s.pdf

Feito, M. (2013). Agricultura familiar para el desarrollo rural argentino. Avá. Revista de Antropología, 1 (23). 139-159. Recuperado de: https://www.redalyc.org/ pdf/1690/169039923006.pdf

Fitting, E. (2007). ¿ La economía natural enfrenta a la global? Desafíos a los debates sobre el maíz mexicano. Bajo el Volcán, (11), p. 17-44. Recuperado de: https://www.redalyc.org/articulo.oa?id=28671103

Gómez L. y Tacuba A. (2017). La política de desarrollo rural en México. ¿Existe correspondencia entre lo formal y lo real? Economía UNAM, 14(42), 93-117. Recuperado de http://www.scielo.org.mx/scielo.php?script=sci_arttext\&pi$d=S 1665-952 \times 2017000300093 \&$ Ing=es\&tlng=es

Guinjoan, E., Badia, A., y Tulla, A. F. (2016). El nuevo paradigma de desarrollo rural. Reflexión teórica y reconceptualización a partir de la Rural Web. Boletín de la Asociación de Geógrafos Españoles, (71). 179-204. doi: https://doi. org/10.21138/bage.2279

INAFED. (2010). Enciclopedia de los municipios y delegaciones de México. Recuperado de: http://www.inafed.gob.mx/work/enciclopedia/EMM13hidalgo/ municipios/13029a.html

INEGI. (2015). México en cifras. Ciudad de México, México: Recuperado de: https://www.inegi.org.mx/app/areasgeograficas/?ag=13

INEGI. (2018). Tabulados de la Encuesta Intercensal 2015 . Recuperado de: https:// www.inegi.org.mx/programas/intercensal/2015/\#Tabulados

Jarquín N., Castellanos J. y Sangerman D. (2017). Pluriactividad y agricultura familiar: retos del desarrollo rural en México. Revista mexicana de ciencias agrícolas, 8(4), 949-963. doi: https://doi.org/10.29312/remexca.v8i4.19

Loor P., Alonso A. y Pérez M. (2019). Las relaciones agrarias en Latinoamérica. Sus manifestaciones en el Ecuador. Economía y Desarrollo, 162 (2). 1-21. Recuperado de: http://scielo.sld.cu/scielo.php?script=sci_arttext\&pi$\mathrm{d}=\mathrm{S} 0252-85842019000200016$

Max-Neef, M. (2010). Desarrollo a escala humana, opciones para el futuro. Santiago, Chile: Biblioteca CF+S.

Navia-Antezana, J. (2008). Servicios ambientales: una opción para el desarrollo sustentable en la cuenca del Cupatitzio, Michoacán. En Paré L., Robinson D. y González M. (Coords). Gestión de cuencas y servicios ambientales perspectivas comunitarias y ciudadanas. (pp. 163-184). Ciudad de México. SEMARNAT, Instituto Nacional de Ecología. Recuperado de http://bibliotecasibe.ecosur. $\mathrm{mx} / \mathrm{sibe} / \mathrm{book} / 000050309$

Quintero M. y Ceballos S. (2007). El sector agropecuario en México, retos y perspectivas para su modernidad, en Quintero M. (Coord.). Contexto nacional e internacional del sector agropecuario, limitantes y perspectivas. (pp. 35-67). Ciudad de México, México. Editorial: Porrúa y Cámara de Diputados.

Robles H. M. (2013). Subsidios al Campo: Los pequeños Productores y la Política Pública. Recuperado de: http://www.senado.gob.mx/comisiones/desarrollo_rural/ docs/reforma_campo/2-III_c2.pdf

Rizzo, N. (2012). Un análisis sobre la reproducción social como proceso significativo y como proceso desigual. Sociológica (México), 27(77), 281-297. Re- 
cuperado de: http://www.scielo.org.mx/scielo.php?script=sci_arttext\&pi$d=S 0187-01732012000300009 \& \operatorname{lng}=e s \& t$ Ing=es.

SIAP. (2016). Anvario Estadístico de la Producción Agrícola. Recuperado de: https:// nube.siap.gob.mx/cierreagricola/

Soto J., González D. y Carrillo M. (2020). El café en la Otomí-Tepehua: estrategias campesinas y cadenas globales de valor en México, 2017 -2018. Revista Científica de Estudios Urbano Regionales Hatsö-Hnini, 1 (3) pp.3-48. doi: https://doi.or$\mathrm{g} / 10.47386 / 2020 \mathrm{~V} 1 \mathrm{~N} 3 \mathrm{~A} 1$

Terrazas A., Garza S. y Cruz R. (2019). Las organizaciones rurales, opciones para la integración de los pequeños productores rurales del sector agrícola en San Buenaventura, Coahuila. Revista Mexicana de Agronegocios, 45(1), 285-298. Recuperado de: https://www.redalyc.org/jatsRepo/141/14162394002/14162394002.pdf

Tortosa, J. M. (Comp.). (2011). Maldesarrollo y el mal vivir. Pobreza y violencia a escala mundial. Quito, Ecuador: Ediciones Abya-Yala. Recuperado de: https://web. va.es/es/iudesp/documentos/publicaciones/maldesarrollo-libro.pdf

Vences K., Bolio J. y Bolio H. (2018). Autopercepción del empoderamiento en mujeres yucatecas. Revista Logos, Ciencia \& Tecnología, 10(1), 28-40. Recuperado de: https://www.redalyc.org/jatsRepo/5177/517754458002/517754458002.pdf

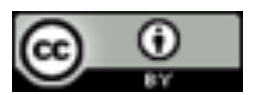

Este es un artículo de acceso abierto bajo licencia Creative Commons Reconocimiento 4.0 Internacional 